\section{They touched the nerve of the Universe}

\section{V.F. Weisskopf}

The Early Years: The Niels Bohr Institute 1921-1930. By Peter Robertson. (Akademisk Forlag, Denmark, 1979.) E6.

THIs book is a short account of the first ten years of Niels Bohr's famous Institute for Theoretical Physics. This institute was the scene of one of the most revolutionary and far-reaching developments in natural science, the birth of quantum mechanics. In some ways it was also the first international scientific institution, not in the sense of being internationally managed, but by having assembled, for shorter or longer periods, groups of young and productive physicists from many countries. Their names include most of the great leaders in physics such as F. Bloch, $\mathrm{H}$. Casimir, P.A.M. Dirac, P. Ehrenfest, G. Gamow, W. Heisenberg, L. Landau, W. Pauli and many others. It was at that time, and with those people, that the foundations of the quantum concepts were created. In lively discussions the deepest problems of the structure of matter were

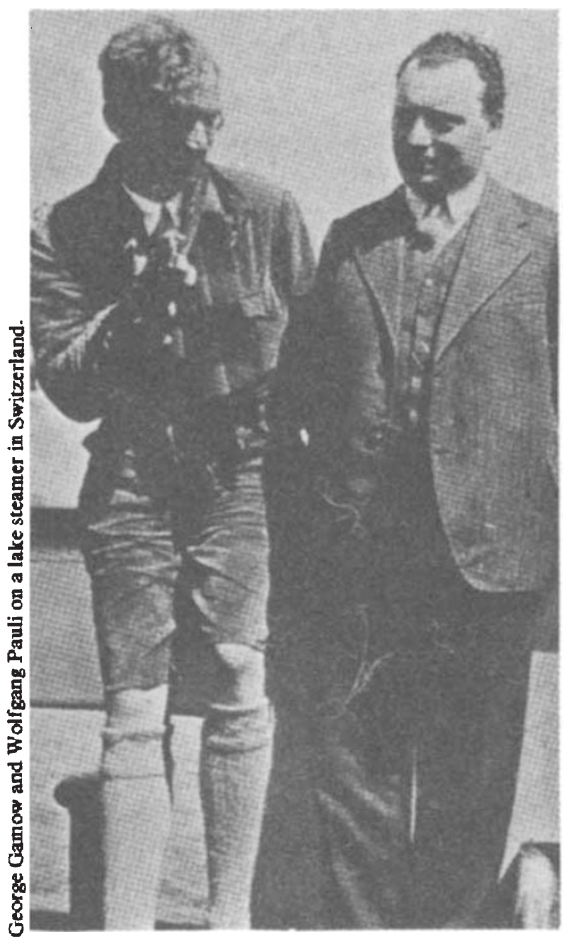

brought to light. N. Bohr was the acknowledged leader; he created a style of thinking, the "Kopenhageuer Geist". The greatest among his colleagues, he was acting, talking and living as an equal among a group of young, optimistic, jocular, enthusiastic people, approaching the deepest riddles of nature with a spirit of attack, a spirit of freedom from

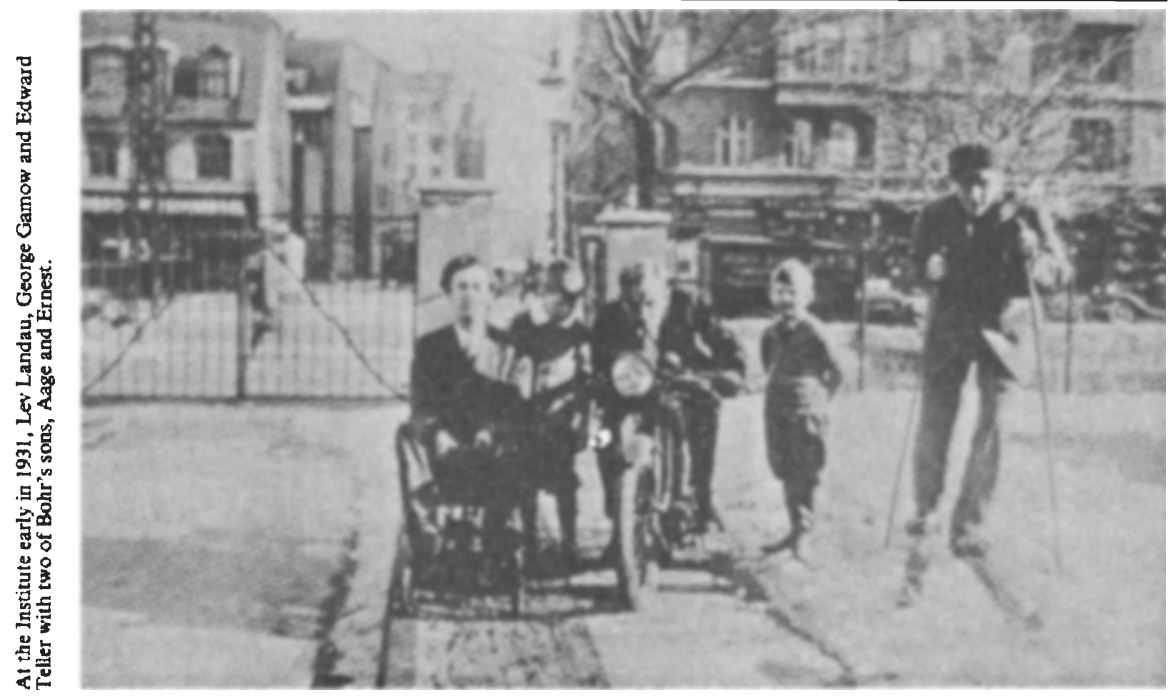

conventional bonds, and a spirit of joy that can hardly be described by anyone who was not there at that time. In this great period of physics Bohr and his collaborators touched the nerve of the Universe. They were able to penetrate into the inner workings of nature that had been a secret up to this point. In the course of a few years only, the basis was laid for a science of atomic phenomena that grew into the vast body of knowledge known to us today.

The book by Robertson tries to recount the events that led to the foundation of that institution and the happenings during its first decisive and creative decade. It is the result of a painstaking research into the history of this unique institution. The author gives a lively and easily readable account in a little more than 150 pages, but one notices that he was not there at the time. We read about the early attempts to create a centre of international physics after the ravages of the First World War had interrupted scientific collaboration; we read about the bureaucratic and financial difficulties that were overcome only with support by the Rockefeller Foundation; we read about the different scientists who came to the institute and about their work and their conversations with Bohr. One of the most attractive features are the many photographs of the institute, of the physicists, singly and in discussions, and of conferences and meetings that had taken place in Copenhagen and elsewhere during that period.

Reading this book and looking at the pictures is a nostalgic experience for those who had the privilege of being in contact with Bohr's institute in one way or another. I am not sure how much of the spirit and of the intellectual achievements of the institute is transmitted to a reader who has not had that great privilege.

V.F. Weisskopf is Institute Professor at Massachusetts Institute of Technology, Cambridge, Massachusetts.

\section{Ape language, cognition and culture}

\section{Carolyn A. Ristau}

The Ape's Reflexion. By Adrian Desmond. Pp. 288. (Blond and Briggs: London; Dial Press/James Wade (Dell): New York, 1979.) $£ 7.95, \$ 10.95$.

The APE'S Reflexion is man; the possibility of the ape reflecting has created recent controversy. Is the ape capable of some primitive language; how extensive are his cognitive abilities; does the ape murder; does he have a sense of self and of death? Adrian Desmond deals with these momentous concerns in what I presume is intended to be a semi-popular book. His writing style is often fluid and he frequently achieves a sense of immediacy, seeming to give an eye-witness account of the research. One can easily nestle down with his book for a few evenings' light reading. The sense of an eye-witness account is apparently not based on any visits by the author to research in progress. This is unfortunate, for an objective, careful and critical reporting of anecdotal information would be a useful addition to the literature on the ape language projects. The scientific literature suffers from a lack of such information while the popular literature abounds with dramatic and careless reports.

Briefly, Desmond's book concerns itself primarily with the ape language research projects, the neuroanatomical comparison of man and chimpanzee, tool use and proto-cultural activities of chimpanzee and early man, and some of Jane Goodall's investigations at the Gombe River Stream Preserve. There are numerous direct quotations from researchers' studies, an index and footnotes. The footnotes, 
located at the back of the book, indicate references and sometimes offer detailed discussions. An alphabetical list of references and more such discussion would have been useful additions. The book also contains 24 pages of black and white photographs, predominantly of chimpanzees from the language projects and the Gombe River Stream.

Desmond considers man's close genetic relationship to the chimpanzee, citing $99 \%$ similarity in DNA nucleotides. Yet he does not note that the $1 \%$ difference appears to control timing and sequence of genetic expression, a mechanism by which from each other. Furthermore, overall genetic similarity or dissimilarity need bear no necessary relation to the similarity of particular attributes of any two species. A dolphin is physically very different from man, yet may have certain cognitive abilities that are similar to man's. Desmond's comparisons between the Gombe River chimpanzee killing and man's act of murder, as well as many anecdotes from the ape language projects, are other examples of dramatic interpretations of data that need further analysis.

Desmond does raise important points. For example, in Desmond's consideration of the ape language work, Wittgenstein's aphorism, "If a lion could speak we could reference to the naive assumption often made by trainers that chimpanzees use signs like 'please' and 'think' with the meanings

Desmond also describes the recent investigation of Savage-Rumbaugh et al. (p.107) into the meaning of an utterance. Their chimpanzees seem to have the ability to use a lexigram or geometric design such as the design for 'key', in a highly specific context, but become bewildered upon its application to a wider array of contexts. organisms can develop very differently not understand him" (p.33), is quoted in assigned to them by humans (p.35).
That is, the chimpanzees seem to recognize that use of the lexigram for key will initiate a chain of events that eventually leads to their obtaining food with a key, but do not seem to understand that the lexigram is the 'name of' a key. Gradually some kind of understanding closer to that level does seem to be achieved, but the research makes it clear that a chimpanzee's (or young child's?) appropriate use of a 'word' in a limited number of contexts does not imply understanding of the word.

However, as Desmond notes, words can 'map on' to thought. Premack conceptualizes his 'ape language' investigation as permitting apes to use words to map out conceptual structures the animal already possesses. The end of the work is thus not to teach an ape language or to wonder how linguistic the apes' abilities are or are not, but to use the ape 'language' as a tool for revealing some of the apes' cognitive capacitics.

Throughout, Desmond wisely emphasizes that we cannot measure apes with a human yardstick.

Another of the more positive parts of Desmond's book is his exciting account of the trail of discoveries initiated by analysing soil samples and leading, finally, to the discovery, in the molecules of soil, of flowers at the grave of a Neanderthal man. Here was an indication of some ceremony for the dead, a remnant of culture in so early a hominid.

In all, Desmond does consider fascinating issues and offers some insightful thoughts. But one wishes at least for less wordiness, more dispassionate writing and less uncertainty about the validity of his interpretations. And does the reader need to find phrases like " $O$ h Darwin, where art thou now?"

Carolyn A. Ristau is Research Associate in Animal Behavior at The Rockefeller University, New York.

the theory was made in 1916 by Gilbert Newton Lewis, who described the chemical bond as a pair of electrons held jointly by two atoms and who emphasized the stability of molecular structures in which each atom is surrounded by the same number of electrons as in a neutral noblegas atom. Important contributions, such as the principle of electroneutrality and possible covalence as large as eight (for nickel in nickel tetracarbonyl), were made by Irving Langmuir from 1919 to 1921 .

Despite some clarification introduced by the new ideas about the electronic structure of atoms and molecules, the theory of valence and the structure of molecules and crystals clearly remained incomplete. Many questions were asked in the first half of the 1920s that could not be answered; for example, why are the aromatic hydrocarbons more resistant to hydrogenation than other unsaturated hydrocarbons, why do complexes of palladium(II) and
New Books in the Life Sciences

\section{Dental Plaque and Surface} Interactions in the Oral Cavity

Edited by S. A. Leach

Proceedings of a workshop held November 1979 at ICI Pharmaceuticals Division, Macclesfield, U.K.

Comprises 20 papers presented under the following session headings:

Surface and colloid phenomena in relevance to the mouth;

Bacterial adhesion to tooth surfaces; Some factors that might affect plaque formation; The tooth-saliva interface.

340 pages. Illustrated

Hard ISBN 0904147150 f18/US $\$ 40$ Soft ISBN0904 147169 £10/US\$23

\section{Saliva and Dental Caries}

Edited by I. Kleinberg, S. A. Ellison and I. D. Mandel

Proceedings of a workshop held June 1978, State University of New York at Stony Brook. Includes 30 papers presented under the following main topic sessions:

Composition and properties of saliva potential determinants in the caries process; Influence of saliva on the caries triad - bacteria, substrate and host; Defense mechanisms and strategies for prevention of dental caries.

In addition reports, conclusions and recommendations for future research were included.

575 pages.

ISBN 091700064 f10/US $\$ 20$

\section{Preference Behaviour and \\ Chemoreception}

Edited by J. H. A. Kroeze

Proceedings of a symposium organized by ECRO. The Netherlands, May 1979.

Contains 24 papers under 4 major topics:

Sensory determinants of preference; Towards a formal view of preference behaviour; Preference in an ecological context; and, Preference as an expression of need, culture and attitudes.

360 pages

ISBN 0904147126

$£ 12 / \$ 26$

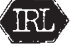

Bel. It was extended in 1893 Werner to include complexes of metals, which he identified correctly from chemical evidence as representing tetrahedral, square planar or octahedral coordination of ligands about a central metal atom. An important contribution to

\section{Information Retrieval}

1 Abbey Street, Eynsham, Oxon, OX8 1JJ, U.K. Fisk Building, Suite 815, 250 West 57th Street, New York, NY 10019, U.S.A. 